\title{
Teoría de la economía de la empresa e interés general $(*)$
}

SUMARIO: A. INTERES GENERAL, FORMAS DE ESTADO Y ORDEN ECONOMICO. B. EL FOMENTO DEL INTERES GENERAL MEDIANTE LOS SUJETOS ECONOMICOS. C. ECONOMICIDAD PROPIA Y ECONOMICIDAD GENERAL. D. FUNCIO. NES ESPECIFICAS DE LAS EMPRESAS DE ECONOMICIDAD GENERAL. E. OTRAS CARACTERISTICAS DEL FOMENTO DIRECTO DEL INTERES GENERAL. F. ALEGATO EN FAVOR DE UNA TEORIA ECONOMICA EMPRESARIAL GENERAL Y TAMBIEN DE UNA PUBLICA. RESUMEN. SUMMARY (1).

\section{A. INTERES GENERAL, FORMAS DE ESTADO Y ORDEN ECONOMICO}

La Constitución de la República Federal de Alemania (RFA), de 23 de mayo de 1949 (BGBl. S. 1), recoge en su artículo 56 la obligación que tiene el Presidente de la República Federal de jurar —en su toma de posesión- que dedicará todo su empeño «al interés del pueblo alemán, a aumentar su beneficio y apartar de él todo perjuicio», etc. En esta fómula queda recogido el precepto principal que inspira la actuación estatal —ocuparse del bienestar de todos- en el que, a su vez, se fundamenta la legitimidad originaria del Estado. No existe

${ }^{*}$ Artículo publicado en la revista Zeitsschrift für öffentliche und gemeinwirtschafliche Unternebmen, año 54, 1984, núm. 3, pp. 238-251. El INAP y la redacción de DOCUMENTACIÓN ADMINISTRATTVA desean dejar constancia de su agradecimiento, tanto al autor como a los editores, por la autorización concedida para la traducción al castellano y publicación del presente trabajo.

(1) Discurso de toma de posesión, presentado en la Universidad de Mannheim el 5 de julio de 1983. 
ninguna sociedad humana que pueda existir a largo plazo sin procurar alcanzar en común y conscientemente este bienestar de todos. El Estado aparece, por tanto, como el administrador de este interés general y su función consiste en asegurarlo y cuidarlo fiduciariamente a cuenta de la sociedad y de sus miembros y en beneficio de aquélla y de los individuos. Entre la sociedad y el individuo se da una tensa relación, y tan es así, que ni siquiera un Estado constitucional ideológicamente neutral podrá escapar de ella, si no quiere verse desnaturalizado y quedar reducido a un mero escenario de las rivalidades de los distintos grupos de intereses. Cada Estado define cuál es el contenido de este interés general y cómo han de estructurarse las relaciones entre el individuo y la colectividad. De la elaboración de los principios que las determinan siempre se han ocupado filósofos, teóricos del Estado, constitucionalistas, economistas y sociólogos; de las decisiones concretas, en cambio, los políticos. No ha de extrañarnos, por tanto, que a la vista de una fórmula vacía, como es la del «interés general», cada uno llegue a dotarla de contenidos totalmente distintos.

Actualmente son dos los que podemos considerar como tipos básicos importantes del fomento del interés general y que además están enfrentados entre sí: el Estado totalitario y el Estado liberal. (Quien prefiera una terminología superlativa usará los términos de Estados totalizador y liberalizador.) En el primer supuesto, el poder estatal tiende principalmente a «abarcar y ordenar todas las formas de vida de una sociedad» (2). El Estado mercantilista de bienestar del régimen absolutista del siglo XVIII, de forma similar a lo que sucede con las constituciones actuales, veía en la reglamentación de las autoridades un método para que el Estado soberano pudiera ocuparse del bienestar de sus ciudadanos. Esta idea ha recibido una serie de críticas por entenderse que mediante tal actividad estatal global la existencia y el desarrollo del individuo queda sensiblemente reducido. En un lenguaje moderno se diría que el Estado social, reconocido como tal, llega a los límites del Estado provisor cuando el ciudadano se convierte en un invitado del Estado sin necesidad de cargar con ningún tipo de prestaciones o de riesgos. El Estado liberal, en una forma totalmente opuesta al totalitario, tiene como fin crear un ámbito de actividad individual que sea lo más amplio posible, de tal manera que cada individuo deberá procurar alcanzar independientemene y bajo su propia responsabilidad su bienestar personal, del cual se derivará el bienestar general.

Fue el médico inglés de origen holandés BERNHARD DE MANDEVILLE (1670-1733) - en un folleto anónimo publicado en Londres en 1714 titulado The Fable of the Bees: of Private Vices, Publick Bene-

(2) Reinhold ZIPPELIUS, Allgemeine Staatslebre (Politikwissenschaft), 8." ed., München, 1982, p. 267. 
fits (3) - el que primero formuló esta idea fundamental. De forma muy aguda relata en él cómo con defectos privados, como el egoísmo y la vanidad, se puede desarrollar una iniciativa empresarial y el interés general. El autor resuelve esta aparente paradoja, señalando que la preservación personal y el amor propio no son más que instintos naturales del hombre. Y más todavía: «Cada uno acepta al otro para ser aceptado él mismo. La adulación se utiliza, en realidad, para tratar de satisfacer las propias necesidades, naturalmente hipócritas, y por ello es un vicio. Pero incluso a través de ésto los hombres se civilizan recíprocamente y lo mejor terminará triunfando» (4). MANDEVILLE entiende que es justamente el vicio el que conduce al interés general, así como la explotación del comercio induce a una mayor circulación de bienes, la vanidad de las mujeres a la producción de bienes y al sustento de los tejedores, de igual modo que la prostitución a la protección de las mujeres y las hijas, la avaricia al fomento de la acumulación, el derroche a la distribución de los bienes, etcétera.

Adam SMITH (1723-1759), en su obra principal filosófico-moral Theory of Moral Sentiments (Londres, 1759) (5), quiere refutar la teoría de MANDEVILLE por su falta de vinculación con las buenas costumbres. No obstante, este autor comparte con MANDEVILLE —n sus lecciones de trascendencia fundamental para la economía nacional $A n$ Inquiry into the Nature and Causes of the Wealth of Nations (Londres, 1776) (6) - la la idea de que cada individuo deberá actuar en su propio interés, pero siempre y cuando se mantenga dentro de los límites de las buenas costumbres. Si esta competitividad se desarrolla dentro del marco de los derechos fundamentales y de la libertad garantizados por el Estado, entonces será la invisible hand la que contribuirá a un desarrollo armonioso de la economía. El interés propio sirve aquí, por tanto, de palanca para el interés general.

Las experiencias habidas hasta ahora nos muestran que el camino para alcanzar el interés general no nos conduce ni a un modelo de Estado totalitario ni a uno liberal. Tanto las ataduras como las libertades excesivas, entendidas como laissez faire, laissez passer, le monde va de lui même, son igualmente perjudiciales para el interés general. En las sociedades occidentales industriales ha surgido un modelo de Estado

(3) Traducción alemana de la 3." edición de Otto Bobertag (ed.), Mandevilles Bienenfabel, München, 1974. Véase también Walther EUCHNER, Egoismus und Gemeinwobl, Frankfurt am Main, 1973, pp. 74-131.

(4) Gerd ROELLECKE, «Gleich und Ungleich», en Der Mensch als Ordnungswaise?, Ein interdisziplinärer Erkundungsgang, Beiträge von Hermann Lübbe u. a., Freiburg y München, 1981, pp. 217-281, aquí p. 251.

(5) Traducción alemana: Theorie der ethischen Gefüble, 2 tomos, Leipzig, 1926.

(6) . Traducción alemana de Adam SMITH, Der Woblstand der Nationen. Eine Untersuchung seiner Natur und seiner Ursachen. Una traducción del inglés y con epílogo de Horst Claus RECK. TENWALD, München, 1974. 
social liberal que reúne en cierto modo elementos de ambos tipos de sociedades. Y dentro de éstos se encuentran algunos países que tienden más hacia conceptos de un Estado de bienestar, otros, en cambio, a un liberalismo económico. La economía de la República Federal de Alemania se incardina más bien entre estos dos tipos, aunque no se ha llegado a un acuerdo entre las fuerzas políticas decisivas ni en la economía nacional sobre lo que ha de entenderse como un equilibrio adecuado. En otras palabras: mientras unos apoyan un reforzamiento del Estado social, otros, por el contrario, pretenden ampliar el régimen de mercado libre, para maximizar así el bienestar en una economía social de mercado.

Es la economía del bienestar la que nos proporciona las condiciones que se han de dar para la obtención del mejor resultado. Según aquélla, se requerirá una determinación de todas las funciones individuales de beneficio y su posterior agregación en una función general, así como una decisión sobre la distribución óptima de ingresos. Sabido es que, según PARETo, el estado óptimo se alcanza cuando ningún miembro de la sociedad puede pasar a mejorar su situación sin que otro tenga que empeorar la suya. Es decir, que habrá que producir un bien o prestar un servicio, siempre y cuando ello mejore la situación de algún sujeto económico sin que empeore la de otro. Lo que pueda ser mejor o peor para un individuo se determina por sus propias preferencias. Esta teoría es la base de un modelo de concurrencia completamente equilibrada, que se apoya asimismo en numerosas presunciones simplificadas de un mercado ideal. La imperfección del mercado y la existencia de efectos externos -es decir, de efectos de actividades empresariales que se desarrollan fuera del mercado y que por ello no permiten una asignación perfecta de los recursos- exige principalmente dos cosas: primero, que se extiendan del mero bienestar económico, entendido éste como el aumento de la cantidad de los bienes y servicios ofrecidos en el mercado, a un bienestar de carácter general para toda la sociedad, o sea, como una función social de bienestar del tipo propuesto por BERGSON-SAMUELSON, que recoge tanto valoraciones éticas como evaluaciones sociales de costes-beneficios. $\mathrm{Y}$ en segundo lugar y en relación con lo dicho, hay que incluir, además, en el cálculo de los sujetos económicos elementos de fomento directo del bienestar. Referente a este presupuesto, la economía de empresas puede aportar aspectos importantes, y a ellos me quiero referir en lo que sigue.

\section{B. EL FOMENTO DEL INTERES GENERAL MEDIANTE LOS SUJETOS ECONOMICOS}

Tanto en la doctrina como en la práctica aparecen el interés individual y el general, el mercado y el Estado, como dos conceptos opues- 
tos; no obstante, esta idea no tiene una aplicabilidad general. Dado que el interés general, y justamente por su carácter de generalidad, incluye al mismo tiempo el interés individual, paralelamente se entiende que el bienestar del individuo es necesario para crear el bienestar general.

Como resultado nos encontramos, aquí y ahora, con un orden económico mixto en el que se equilibran las libertades y las obligaciones para el individuo y la sociedad, lográndose con ello la síntesis a un nivel más alto. A estas alturas nadie puede discutir seriamente el bienestar que nos ha proporcionado la economía del mercado social, que era impensable hace siglos y nunca se había alcanzado con anterioridad (aunque no niego, por otro lado, que haya individuos que tiendan hacia un mayor bienestar individual y general, así como otros que puedan estar satisfechos con menos). Sólo moviéndose en un marco de generalidad deberá y podrá el individuo satisfacer sus necesidades. Pero uno no debe limitarse - cosa que sucede muy a menudo- a unas relaciones de mercado reducidas a las existentes entre oferentes y demandantes, productores y consumidores, ya que la participación de los sujetos económicos en la economía y su contribución al bienestar e interés general es muy amplia y variada. Para entender esta interrelación, habrá que estudiar previamente los diferentes sujetos económicos.

Las ciencias económicas incluyen dentro del concepto de sujetos económicos todas aquellas unidades (empresas, economías de empre$\mathrm{sa}$, economías particulares, instituciones, organizaciones, personas físicas) que se rigen por un plan económico autónomo. No es necesario que éste esté fijado por escrito, siendo suficiente que se puedan tomar - según criterios y objetivos propios- las decisiones pertinentes sobre los bienes económicos (es decir, respecto de los bienes escasos, adecuados y accesibles). De manera consciente he escogido este planteamiento general, pues engloba también a los sujetos económicos, y con ello, a su vez, los objetivos de conocimiento de la ciencia económica que no persiguen fines de ganancias económicas o no lo hacen de manera exclusiva. Como consecuencia de la evolución histórica se suele tener en cuenta como sujetos económicos, en primer lugar, a las personas físicas, quienes en su condición de economías domésticas uni o pluripersonales suelen tender a su propia realización entendida como una forma cualificada de conservación de sí mismos. Mediante la obtención de unos ingresos aseguran su independencia económica. Desde un punto de vista empresarial son las empresas, el segundo tipo al que nos hemos referido, el más estudiado. En un sentido estricto se trata de aquellas empresas con ánimo de lucro que se financian ellas mismas mediante los ingresos obtenidos por su actividad. Un tercer grupo de sujetos económicos queda englobado bajo el concepto general de asociaciones, en el que hay que incluir a los sindicatos, a las cá- 
maras o colegios profesionales, a las asociaciones, a las sociedades y demás organizaciones sin ánimo de lucro. Su función es cubrir las necesidades de los grupos y su autonomía se garantiza a través de las aportaciones de sus miembros. Por último, nos encontramos ante las Administraciones públicas que, englobadas entre los tipos de sujetos económicos mencionados, basan su existencia en las contribuciones generales (impuestos, tasas y derechos) y en la función de cubrir las necesidades generales.

Entre estos tipos ideales se encuentran, por supuesto, diversas gradaciones. Escogeré aquí de entre los múltiples sujetos económicos existentes a las asociaciones de Cáritas y a las organizaciones eclesiásticas con todas sus instituciones (que se cifran en unas mil) (7). Muchos de ellos, aunque se presentan como empresas, ofrecen rasgos característicos tanto de asociaciones como de Administraciones. Suelen financiar sus objetivos, por un lado, a través de ingresos que cubren los gastos, como pueden ser costes de asistencia u otro tipo de precios administrativos, y por otro lado, mediante subvenciones que pueden provenir en parte de cuotas o de contribuciones (con lo que se pone de manifiesto su carácter de asociación o de Administración, respectivamente).

$\mathrm{Al}$ igual que las economías domésticas y las empresas, las asociaciones y las Administraciones contribuyen, si bien de manera muy distinta, al interés general. En otras palabras, unas fomentarán este interés general y las otras actuarán a costa de éste. Hay que decir, no obstante, que el citado interés general no es un principio exactamente definible, pues se compone del conjunto de los diversos intereses y se forma por decisiones políticas que dependerán, a su vez, de cada modelo estatal y orden económico existente. El interés general es un concepto que va más allá de un bienestar económico o de la prosperidad, si éstos se entienden como la mejora de ingresos o se refieren al bienestar global de todos. Desde un punto de vista empresarial todos los sujetos económicos contribuyen de manera indirecta $\multimap$ fomentan de forma directa - el concepto, realmente vago, de interés general (8). Dentro del primer tipo se pueden englobar la mayoría de economías domésticas y empresas, aunque se encuentren también aquí personas e insti-

(7) Véase del autor «Diakonische Zielsetzungen und unternehmerische Entscheidungen in der Diakonie», en Soziale Arbeit, núm. 12, año 31, 1982, pp. 532-539.

(8) A pesar de la vaguedad del interés general hay que esforzarse por alcanzarlo: de igual forma que no se puede precisar con exactitud hasta qué punto los aumentos de precio están condicionados por la desvaloración de la moneda o los avances técnicos, pero por razones de política económica hay que tratar de remediarlo. Otro supuesto ilustrativo: nadie puede fijar con exactitud dónde acaba el pleno empleo y dónde comienza el paro y, aun así, el pleno empleo sigue siendo un objetivo de la política económica. Algo parecido sucede también con los objetivos empresariales. Las empresas tienden a una conservación del capital, aunque éste no pueda ser evaluado con exactitud. 
tuciones que trabajan directamente en pro del interés general. Al segundo grupo pertenecen, en cambio y sobre todo, las empresas públicas, así como las asociaciones y las Administraciones.

\section{ECONOMICIDAD PROPIA Y ECONOMICIDAD GENERAL}

De acuerdo con lo dicho anteriormente habría que clasificar a los sujetos económicos según estén orientados principalmente hacia una economicidad propia o hacia una general. A continuación se explicará ésto en lo que atañe a las empresas aunque lo esencial de las explicaciones puede decirse también de las Administraciones públicas. En las empresas que se rigen por principios de economicidad propia predominará el interés empresarial: concepto integrado por un conglomerado de intereses de conservación de capital, pago de dividendos, sueldos altos, prestaciones sociales, participaciones y garantías de trabajo. Serán, por tanto, los propietarios de capital, así como los miembros de la empresa, los que tendrán, en primer lugar, provecho de ella. No obstante, es necesario subrayar aquí que sus prestaciones también aportarán indirectamente beneficios a los clientes, los proveedores, bancos y Estado. Por el contrario, las empresas orientadas hacia una economicidad general están directamente al servicio del interés general común (instituciones para minusválidos o para estudiantes, empresas de transportes de cercanías).

Pero, antes de seguir, creo necesarias algunas aclaraciones terminológicas previas: las empresas de economicidad general pueden actuar en base a propiedad privada o pública (estatal o comunal). Teniendo en cuenta la economía pluralista en la que nos desenvolvemos, vemos que la propiedad privada no se limita a las empresas de economicidad propia, sino que también se da en las de economicidad general. Como ejemplo quiero citar en este lugar a las empresas dedicadas a la beneficencia (9), pero también a los partidos, asociaciones, sindicatos (10), fundaciones e iglesias, así como las empresas de titularidad privada para la edificación de viviendas de interés general (11) y algunos colegios profesionales (12). Y, por el contrario, las corporaciones

(9) Vid. Gottfried THERMANN, «Einrichtungen der Diakonie als gemeinwirtschaftliche Unternehmen», en Zeitscbrift für öffentliche und gemeinwirtschaftliche Unternebmen, tomo $2 .^{\circ}, 1979$, pp. 443-456; Heinz NLEDRIG, «Bemerkungen zur ökonomischen Bedeutung der freien Wohlfahrtspflege», en la misma revista, tomo $3 .^{\circ}, 1980$, pp. 237-239.

(10) Vid. Achim von LOESCH, Die gemeinwirtschaftlichen Unternebmen der deutschen Gewerkschaften, Entstebung-Funktionen-Probleme, Köln, 1979.

(11) Vid. Helmut W. JENKIS, Die gemeinnützige Wobnungswirtschaft zwischen Kritik und Reformvorscblägen, Frankfurt am Main, 1980.

(12) Vid. Werner Wilhelm ENGELHARDT, «Gemeinwirtschaftliche Genossenschaften-ein möglicher Widmungstyp von Genossenschaften unter sechsen», en Zeitschrift für öffentliche und gemeinwirtschaftliche Unternebmen, tomo 6., 1983, pp. 30-47. 
territoriales, Bund, Länder y municipios no sólo disponen de empresas orientadas a la economicidad común, como se comprueba por el hecho de que la mayoría de las 928 participaciones de 1981 (13) directas e indirectas del Bund (con, por lo menos, el 25 por 100 del capital nominal) perseguían objetivos de economicidad propia, y lo mismo se puede aplicar a los bancos, industrias y empresas de suministros eléctricos de los Länder y a las Cajas de Ahorro de los municipios; siendo estas últimas las que mejor muestran que además de los objetivos de economicidad propia se valoran los de economicidad general.

Esta dualidad de objetivos a la que se ha aludido - a saber: la economicidad propia y la común- es un presupuesto relativamente frecuente en las empresas públicas. Su finalidad es el fomento directo del interés general a través de unas empresas que actúan con la suficiente capacidad conforme al mercado. Sin embargo, esto conlleva, a su vez, innumerables problemas. No sólo se trata de establecer los objetivos prioritarios, sino también de determinar en qué medida es posible combinar objetivos formales de economicidad propia (como la conservación nominal o real del capital) con otros objetivos ampliados por categorías de economicidad general de beneficios para los usuarios en concreto y en términos generales para los ciudadanos. En cualquier caso hay que tener en cuenta, además, que los bienes declarados de economicidad propia y común no son idénticos a los que persiguen beneficios o se limitan simplemente a satisfacer necesidades, aunque desde luego resultan emparentados entre sí. Esta última pareja de objetivos se refiere a lo siguiente: por un lado lograr ciertas ganancias, es decir, rentabilidad, y por otro cubrir las necesidades. En el «derecho del beneficio común» se equipara la economicidad propia con la ganancia. El $₫ 55$ de la Abgabeordnung (Ley Tributaria) de 16 de marzo de 1976 ( $B G B l$. I S. 613; BStBl. I S. 157), modificado por última vez mediante artículo 13 de la Ley de 20 de agosto (BGBl. I S. 1545; BStBl. I S. 589), determina que para una deducción fiscal es necesario que las empresas actúen con criterios de desinterés. Y en el mismo lugar se encuentra una definición de esta actuación, que dice los siguiente: «se tratará de un fomento o una subvención de carácter desinteresado, cuando no se persigan en primer lugar fines de economicidad propia como, por ejemplo, fines comerciales $u$ otro tipo de fines lucrativos». Esta equiparación no puede aplicarse sin más a las empresas públicas, ya que aquí la pretensión de lucro va más allá de los objetivos de la economicidad propia. El que una actividad tenga carácter lucrativo quiere decir que el capital invertido se administrará en función de una

(13) Bundesministerium der Finanzen (ed.), Beteiligungen des Bundes 1981, Bonn, 1982. Vid. Fritz KNAuss, Die Beteiligungen des Bundes, Schriftenreibe Gemeinwirtschaft, Köln y Frankfurt am Main, 1978. 
ampliación de éste. El supuesto contrario se da cuando solamente se pretenden cubrir las necesidades creadas. Una empresa pública que primordialmente actúe con este objetivo tendrá que producir las prestaciones que cubran aquellas necesidades comunes que de otro modo no puedan ser satisfechas o no lo fueren de manera aceptable. En las empresas públicas este predominio de la tendencia a cubrir los gastos frente a un ánimo de lucro se plasma de manera muy concreta, como puede ser que la parte productora de ganancias prescinda desde un principio de las posibles ganancias que se obtengan (por ejemplo, instituciones de investigación a gran escala, hospitales, sociedades de ferias y exposiciones, instituciones de ayuda al estudiante, empresas de tráfico, empresas de construcción de viviendas) o el que la parte administradora de los beneficios destine los beneficios obtenidos a cubrir otras necesidades (como los Correos Federales Alemanes, Deutsche Bundespost, centrales eléctricas, bienes forestales, institutos de crédito, filiales de publicidad o centros radiofónicos, etc.). En las empresas públicas de economicidad general esto adquiere rasgos análogos: mediante la aplicación correspondiente de las ganancias (por ejemplo, en forma de entregas al ente público matriz) podrá actuar en el mercado y, por supuesto, obteniendo ganancias. Finalmente, la economicidad propia y la común serían siempre compatibles cuando el ente público matriz mantenga su empresa para atender su consumo propio (como, por ejemplo, una empresa de suministros).

\section{FUNCIONES ESPECIFICAS DE LAS EMPRESAS DE ECONOMICIDAD GENERAL}

Si se confrontan las empresas de una orientación de economicidad propia o de lucro con las de economicidad general o de satisfacción de necesidades, hay que señalar que las primeras tienen la ventaja de perseguir objetivos formales operacionales, mientras que los objetivos materiales son de difícil determinación. Los resultados de las primeras se reflejan en términos de beneficios mercantiles, los de las segundas, en cambio, alcanzando los objetivos y cumpliendo con las funciones públicas, que se manifiestan, a su vez, en unos beneficios netos (entendidos como la diferencia entre el beneficio social y los costes sociales), que tendrán que ser verificados mediante balances sociales y otro tipo de cuentas empresariales de rentabilidad general, es decir, de coste social o en relación con el medio ambiente. Dado que el fomento directo del interés general sólo podrá ser garantizado a largo plazo por una empresa manteniéndose ésta, se podría señalar como una posible orientación el que las empresas de rentabilidad general deberán tender a alcanzar una maximalización de las prestaciones sociales con los 
mismos gastos. Expresado en términos mercantiles, esto quiere decir que hay que aumentar las prestaciones para el interés común o para un grupo de destinatarios determinado teniendo siempre en cuenta los efectos secundarios. Con ello nos referimos a todo tipo de restricciones derivadas de los costes en relación a la producción, capacidad, financiación, seguridad, flexibilidad, etc. Para evitar los efectos negativos externos habrá que elaborar un sistema muy restrictivo de estas limitaciones. Siguiendo este método, será también el mercado el que precise lo que se entiende como beneficioso, pues tanto la cantidad como el precio deberán regirse por esto. Otra dirección orientativa determina que las empresas de rentabilidad general deberían intentar que determinadas prestaciones de utilidad sean producidas y ofrecidas causando un gasto mínimo. Aquí será la empresa la que fije cuál será el tipo de las prestaciones, en qué cantidad tendrán que ser producidas y a qué precio se ofrecerán.

Dado el amplio número y diversidad de tipos de prestaciones aportadoras de utilidad de las empresas de economicidad general, es imposible señalar aquí a todos los que se presentan. No obstante, se puede distinguir tres funciones principales (14). Por un lado se trata de estimular los ámbitos que requieran un determinado fomento, es decir, la modernización de la economía nacional. Está demostrado que, en vista de los largos períodos necesarios para la investigación y el desarrollo de productos, procedimientos y tecnologías nuevas, eficientes y con futuro y el alto riesgo de mercado y capital que conlleva, muchas empresas ya no están dispuestas ni están capacitadas para elaborar las innovaciones de base. Por lo demás, gestionan únicamente sus propios intereses - lo cual es perfectamente lógico y legítimo-, de tal manera que sus objetivos se limitan a aquello que consideran que pueda serles rentables. Las empresas de economicidad general están sometidas, en cambio, a la obligación de regular ámbitos que requieren un control; lo que, por lo demás, no ha de identificarse con una reglamentación como la haría el Estado mediante limitaciones de acceso al mercado, prescripciones administrativas de precio, calidad y condiciones, obligaciones contractuales, etc. Aquí se trata, más bien, de una limitación propia respecto de los precios, productos, condiciones de compra y venta, para poder influir en la economía de mercado, así como un factor de orden social. Este tipo de limitaciones autoimpuestas al régimen del libre desarrollo de una competencia equilibrada debe evitar, dado un tamaño determinado de la empresa de economicidad general, que se den en un sector o en una región concentraciones o

(14) Cfr. del autor «Unternehmen im Dienst des Gemeinwohls», en Öffentliche Wirtschaft und Gemeinwirtschafi, año 32, 1983, pp. 6-8; ídem, «Aufgaben und Ziele öffentlicher Unterneh. men in der sozialen Marktwirtschaft», en Der Nabverkebr, año 1, 1983, pp. 8-13, aquí p. 10. 
incluso monopolios no deseados, excluyendo la posibilidad de que pueda crearse una explotación parasitaria de los consumidores (con unos precios muy superiores a los de los costes) o una concurrencia ruinosa (precios que temporalmente no cubran ni tan siquiera los costes). Pero también entiendo que otra de las principales funciones de estas empresas es complementar aquellos ámbitos que lo necesiten. Si faltan las infraestructuras necesarias y el sector privado renuncia a esta actividad o con ella no se obtienen los efectos deseados, entonces se requerirá la presencia de empresas de economicidad general si se quiere asegurar el futuro y garantizar la continuidad de las prestaciones vitales.

He de renunciar en este lugar a entrar en una descripción detallada de la función instrumental que tienen las empresas de economicidad general en mano pública (15). Pero creo que ha quedado suficientemente claro, tras mi exposición anterior, que la supuesta contraposición entre el mercado y el Estado no siempre es tal. Ya que el Estado -más concretamente el Bund, los Länder y los municipios-cumple parte de sus funciones públicas con ayuda de empresas, ello ha provocado también algunas críticas, hablándose incluso de privatización. Creo, por mi parte, que no se puede objetar nada en contra si se trata de empresas públicas que no cumplen (ya) con una tarea de economicidad general, es decir, pública, y están orientadas a una economicidad propia, es decir, se han convertido en una especie de fin en sí mismas. Y por esta razón habrá que comprobar que siempre y en cada caso, y hasta qué punto, nos encontramos ante funciones públicas que hacen recomendable y justifican la actuación de empresas de economicidad general. Si se llegase a una conclusión positiva, entonces surgiría la cuestión de quién ha de ser el titular de tales empresas de economicidad general. Se puede tratar tanto de una Corporación territorial o varias en conjunto (las llamadas empresas públicas mixtas), de uno o varios titulares públicos junto con privados (las llamadas empresas de economía mixta) y de una o varias corporaciones ideológicas (privadas). Una alternativa a la realización de las tareas públicas puede encontrarse también en empresas privadas (de economicidad propia y/o de lucro), que actúan, por ejemplo, en régimen de concesión o de alguna otra forma (las empresas sometidas al Derecho público). Sin embargo, no puede pasarse por alto que el cumplimiento de las funciones públicas es en primer lugar cuestión de las Administraciones, antes de pasar a pensar en el cumplimiento por parte de una empresa.

(15) Vid. Theo THIEMEYER, Wirtschaftslebre öffentlicber Betriebe, Reinbeck bei Hamburg, 1975, pp. 60-109. 


\section{E. OTRAS CARACTERISTICAS DEL FOMENTO DIRECTO DE INTERES GENERAL}

De la teoría económica de la empresa hay que esperar que elabore consideraciones funcionales $\mathrm{e}$ institucionales como las mencionadas, que vendrían igualmente muy bien a la teoría de los bienes públicos, tan influenciada por la ciencia financiera, dado que no es suficiente la mera investigación de las características de los bienes públicos, de su fundamentación y de sus efectos. Se requiere, más bien, una teoría global de las funciones públicas y de su cumplimiento. Las instancias políticas legitimadas para ello son las que, partiendo de un interés público, habrán de señalar los objetivos públicos entendiéndolos como situaciones deseadas, y que en concreto se reflejan en objetivos sociales, estatales, económicos y de especialidad política. De éstas habrá que deducir luego las funciones públicas concretas, que se transformarán en sectores de actividad determinados, como el fomento de la investigación, sanidad, comunicación radiofónica, tráfico, fomento de la economía, etc. Una vez determinado esto, entrarán en juego aspectos de interés empresarial, como es la forma y el modo del cumplimiento de tales funciones. Estas tienen que ser rentables; lo que queda por resolver es, sin embargo, quién y cómo tienen que actuar: si las Administraciones públicas u otros sujetos económicos, si de forma soberana o conforme a las reglas del mercado. Hasta ahora prácticamente no se ha tratado esta decisión fundamental - que tampoco aparece en las discusiones en torno a la privatización-, ya que la definición de funciones, o en su caso de bienes públicos, no conlleva automáticamente la fijación de la forma de producción ni de una oferta pública, privada o mixta; ni, por otro lado, el tipo de financiación a la que esté sujeta, ya sea a través de economías públicas, del mercado o de estas dos fuentes. Estas combinaciones de tres elementos elevados a la tercera potencia son perfectamente posibles, y en parte incluso existentes, si bien harto desconocidas. En otras palabras, lo que se quiere decir aquí es que no importa si se trata de funciones o bienes públicos, puesto que lo esencial, en definitiva, es por qué tipo de producción, oferta o financiación se opta.

Tratándose de la producción y dación privada de las prestaciones en el mercado, habrá que asegurarse de que las actividades consideradas como públicas no se desvirtúen por el hecho de haberse privatizado sus elementos específicos. Se podría decir, por tanto, que la economía de mercado social requerirá, en relación a sus funciones públicas, un control más intenso a medida que se vaya privatizando más. Se plantea en este lugar la cuestión de una posible generalización de esta afirmación: ¿Es necesaria una mayor economicidad general en una 
economía de mercado social que fomenta un comportamiento de economicidad propia? Dándose una mayor competencia en sentido paretiano, ¿se requerirá también un mayor fomento directo de los intereses generales? $\mathrm{Y}$ no es menos cierto que ante una creciente actividad constructora entra - cada vez más a menudo- en juego el artículo 14.2 de la Constitución alemana que señala que la «propiedad obliga. Su uso debe servir al mismo tiempo al bienestar de todos». De todas maneras me parece desmesurado deducir de ello que nos dirigimos a un orden económico de economicidad general y espero haberme expresado con la suficiente claridad: la economicidad general es un objetivo de algunos sujetos económicos, que como instituciones descentralizadas forman, a su vez, una parte integrada en la economía social del mercado. Y sería deseable que las connotaciones que conlleva el uso del término de economicidad general no cobrase tanta importancia. La prioridad de algunos objetivos materiales, y al mismo tiempo su indeterminación, dificultan -incluso a algunos colegas empresarios- el trabajo de valorar la importancia de las empresas de economicidad general, sin mencionar ya la investigación de éstas. ¿Cuántos malentendidos se encuentran bajo el concepto de «economicidad general» en Eugen SCHMALENBACH (16)? Para este autor se trata del cálculo de los precios de compensación internos de la empresa y de los precios según el llamado tipo proporcional. Esto corresponde a los costes (medios) de la última actividad y conduce, por ende, a un grado de ocupación en el que los costes por unidad quedan reducidos al mínimo. Según ScHMALENBACH esto sería la mejor aplicación de rentabilidad general de los factores y ello sería oportuno tanto empresarial como económicamente (17). Creo, no obstante, que en lo que a la valoración de la rentabilidad se refiere, se trata de una afirmación insuficiente, ya que en definitiva sólo se puede interpretar con vistas a la economicidad propia. SCHMALENBACH no ha aportado nada nuevo al interés general, pues lo que escribió sobre la economicidad general deberá ser interpretado, a su vez, como reacción a los reproches que él formuló en su día a la consideración de la teoría empresarial como una teoría del lucro.

Una empresa que actúa con vistas a una rentabilidad común se preocupará de atender a los efectos externos de su actividad y tratará

(16) Eugen SCHMALENBACH, «Selbstkostenrechnung I», en Zeitschrift für bandelswissenschaftliche Forschung, 1919, pp. 257-299 y 321-356, p. 342; ídem, Selbstkostenrechnung und Preispolitik, 8." ed., Köln und Opladen, 1963, pp. 144-151.

(17) Ultimamente ha tratado el tema de forma acertada Dieter SCHNEIDER, «Schmalenbach und der gesellschaftliche Bezug in der Betriebswirtschaftslehre», en Zeitschrift für betriebswirtschaftliche Forschung, año 31, 1979, pp. 799-828; idem, Feschichte betriebswirtschaftlicher Theorie, München, Wien, 1981, pp. 134-137 y 140-143; vid. además ídem, «Zielvorstellungen und innerbetriebliche Lenkungspreise in privaten und öffentlichen Unternehmen", en la revista citada, año 18, 1966, pp. 260-275. 
de evitar por si misma las emisiones perjudiciales para el medio ambiente sin esperar a una regulación legislativa que obligue a una internalización de los costes. La consideración de todos estos efectos que discurren fuera del mercado tiene como consecuencia inmediata que, por ejemplo, ya no se dará una dirección errónea del capital, pues éste se orientará por la contribución general de la empresa al bienestar, sin limitarse sólo a medidas de tipo de costes empresariales, ingresos y ganacias. La teoría empresarial también ha estudiado cuestiones parecidas aunque con un planteamiento más estricto, a saber: la inclusión de los llamados factores imponderables en la toma de decisiones sobre la inversión. Aquí ya se ha hecho mención, además, de los intentos de complementar el cálculo mercantil con cálculos de índole social, y ya existen también varias propuestas para solucionar los problemas de valoración (18).

No obstante lo dicho, es necesario relativizar algunos de los conocimientos empresariales adquiridos que se manejan como seguros, si se quieren aplicar a empresas que se encuentran directamente responsabilizadas del interés general. Por ejemplo, no se puede aplicar en la toma de decisiones como una regla inalterable el reparto de los costes fijos en costes inútiles y útiles o la sustitución (tan deseable desde el punto de vista económico y empresarial) de los primeros por los últimos en el aumento de la producción de las empresas de rentabilidad común. En estos supuestos se trata, más bien, de elaborar como objetivo material la reserva de capacidades para un caso de urgencia (reservas de petróleo, camas de hospital, depósitos de medicamentos, parques automovilísticos, etc.) y no pretender una mejora del grado de aprovechamiento ni mayor grado de empleo. Nos encontramos que aquí los costes inútiles ya son según los objetivos planteados costes útiles.

Si las centrales eléctricas cumplen con su tarea pública y se rigen en sus decisiones por la economicidad propia teniendo en cuenta, a su vez, la general o viceversa, entonces se encontrarán ante la antinomia de querer vender electricidad y al tiempo respetar sus recursos energéticos. ¿Dónde se encuentra el precio óptimo para las empresas, los titulares, los consumidores y la economía nacional? La regulación de las necesidades a través de precios administrativos es un tema muy delicado, tanto para las empresas de economicidad común como para las Administraciones públicas, que no deben dejarse sólo en manos de los políticos. Por lo menos, éstos deberían tener conocimiento de los costes empresariales y económicos y de cuándo los tipos de asistencia de

(18) Vid. Meinolf DIERKES y Raymond A. BAUER (eds.), Corporate Social Accounting, Nueva York, Washington, Londres, 1973; Peter EICHHORN, Gesellschaftsbezogene Unternebmenrechnung. Schriften der Komission für Wirtschaftlchen und sozialen Wandel, tomo 30, Göttingen, 1974, y Klaus von W/YSOCKI, Sozialbilanzen, Stuttgart, New Uork, 1981. 
los hospitales no reciben ningún descuento, o de cuándo, por razones de unificación de tarifas a nivel federal, se aplica a las tarifas de radio el procedimiento de perecuación media o se aprueban leyes sin tener en consideración los efectos económicos de su aplicación administrativa.

Los Ferrocarriles Federales se hubiesen encontrado ante una manifiesta infracción del deber de cumplir con las tareas de utilidad común, recogido en el $\$ 28$ de la Bundesbabngesetz (Ley de los Ferrocarriles Federales) de 13 de diciembre de 1951 (BGBl. I S. 955), si se hubiesen realizado efectivamente hace unos años los planes para una red ferroviaria óptima bajo aspectos empresariales. La reducción de costes viarios a un mínimo es un aspecto del cumplimiento de sus funciones; pero también existe otro: alcanzar un servicio de comunicación suficiente, confortable, seguro, puntual y social bajo unos objetivos y aspectos de política de tráfico, energía y del medio ambiente. Se trata, pues, aquí de déficits que se derivan de las prescripciones legales y de errores de la dirección, o - por otro lado- no es ni siquiera posible establecer una comparación adecuada con otro servicio de locomoción, ya que los Ferrocarriles Federales tienen que financiar ellos mismos su «red vial», mientras que los segundos, en cambio, disponen de los presupuestos públicos. La teoría empresarial deberá pronunciarse sobre el cierre de oficinas de correos o de otras oficinas (por ejemplo, financieras, de sanidad, suministros de agua, navegación). El tamaño óptimo de la empresa se encuentra en aquéllas que cuenten con una intensidad de público suficiente y una elasticidad reducida de demanda y no dependa, por tanto, de costes empresariales mínimos medios calculados a largo plazo. El tamaño óptimo de tales empresas mopolísticas dependerá también de lo que le cuesta al ciudadano acceder a ellas, ya que un ahorro de costes de la empresa puede traspasarse fácilmente al público y ser sobrecompensados de esta manera. Se requerirá, por tanto, una efectiva planificación de la distribución territorial de las oficinas en función de una relación adecuada entre la prestación y los costes, así como entre costes y beneficios. Nos encontramos, pues, con que la teoría empresarial y la logística tienen que complementar sus resultados e incluso probablemente también modificarlos.

\section{F. ALEGATO EN FAVOR DE UNA TEORIA ECONOMICA EMPRESARIAL GENERAL Y TAMBIEN DE UNA PUBLICA}

Desde un punto de vista empresarial se podría prolongar sin dificultades la enumeración efectuada de los problemas que surgen en el fomento del interés general, los cuales provienen fundamentalmente de tres causas: por lo pronto nos encontramos ante unos objetivos de 
características muy específicas, en los que las decisiones que les conciernen no se efectuarán tomando como parámetro los objetivos formales de las ganancias y rentabilidad elaborados por la teoría empresarial, sino que lo serán en primer lugar por objetivos materiales, como los programas en las instalaciones radiofónicas, el abastecimiento local en los establecimientos municipales y la asistencia sanitaria en los hospitales. Y si no se tienen en cuenta las empresas sino las Administraciones públicas, entonces quedará reflejada aún más claramente la prioridad de estos objetivos materiales, como suele ser, por ejemplo, con la protección de las aguas, seguridad interior, fomento de la urbanización ciudadana y concentración parcelaria. Estos objetivos materiales se pueden imponer externamente o elaborarse internamente; pero su cumplimiento siempre servirá en primer lugar a la generalidad. Normalmente se trata de objetivos harto complejos y de muy difícil evaluación, que sólo podrán encontrar un determinante común a través de unos indicadores. En segundo lugar, en los mercados de suministro y entrega, ni la oferta ni la demanda suelen venir determinadas por el principio de equivalencia y contraprestación, ya que ordinariamente se entra en una relación de materias en que sólo una parte se desarrollará en las condiciones del mercado y a veces incluso fuera de éstas. Pero, por regla general - y en tercer lugar-, aparecen unas condiciones jurídicas y reales muy singulares, que tendrán otros efectos sobre las instituciones y las personas físicas que los que se dan en los supuestos de empresas que actúan en el mercado bajo los principios de concurrencia (siendo éste, por cierto, el tema preferido de estudio de la actual teoría empresarial).

Teniendo en cuenta su principio de identidad de la economicidad, la teoría empresarial debería estudiar a fondo las siguientes cuestiones: $¿$ Cuáles han de ser los sistemas de objetivos materiales para las empresas y Administraciones que están al servicio directo del interés general? ¿Qué técnicas de cálculo permitirán la verificación del alcance de éstos objetivos? ¿En qué supuestos se podrán efectuar estas funciones de conformidad al mercado y en cuáles sólo de manera soberana? ¿Pueden aplicarse los conocimientos del marketing, por ejemplo, a la sanidad pública y, en su caso, con qué modificaciones? ¿Cómo pueden ser incrementadas las prestaciones para el interés general sin estar sometidas a la concurrencia del mercado? ¿Se puede hablar de incentivos suficientes para el mercado cuando se trata de estilo de dirección, reconocimiento, ascenso y formación del personal, principio de servicio y ética profesional, o hay que recurrir a otro tipo de mecanismos? (En lo que a los catedráticos se refiere tenemos, por cierto, algo parecido en las cuestiones de la reputación y contratación por las Universidades.)

La teoría empresarial se ha convertido, sobre todo después de la segunda guerra mundial y de la publicación de los Fundamentos de la 
teoria empresarial de Erich GUTENBERG en los años 1951 y 1955, en una doctrina de las empresas privadas. La mayoría de los manuales que se publican hoy con el título de Teoría general de la empresa sólo son una teoría económica de la industria, quedando las empresas de economicidad general, las economías domésticas privadas, asociaciones y Administraciones públicas relegadas a un segundo plano con poca importancia. Las economías domésticas sólo se estudian como consumidores de los bienes producidos; las asociaciones y las Administraciones se definen como non-profit-organizations, no siendo más que un apéndice de la sociedad y la economía. (Por supuesto estoy hablando aquí de la regla general que queda confirmada por las excepciones.) En todos estos casos se desconoce la importancia de estos sujetos económicos para una economía social de mercado, no obstante ser imprescindibles para su funcionamiento. Sin incluir estos sujetos económicos, la teoría empresarial queda incompleta y los conocimientos elaborados por lo que hasta ahora ha sido el estudio de la teoría general de las empresas no pueden ser sino parciales. Por causa de la inexistencia de métodos adecuados no se puede realizar una comparación sobre un posible incremento de economicidad y, en su caso de eficiencia, entre los sujetos económicos arriba clasificados en los diferentes modelos. Por todo lo dicho resulta necesaria una verdadera teoría general de la empresa, que englobase, describiese y estudiase las economías domésticas, las empresas, las asociaciones y las Administraciones públicas.

Pero todo ello no es suficiente, ya que las características específicas de las empresas públicas y de economicidad general requieren de una doctrina especial que atienda a sus problemas concretos. Sobre todo, las autoridades del Bund, de los Länder y de los municipios deben ser objeto de los adecuados estudios empresariales. Y, a veces, tengo la impresión de que los principios - citados tan a menudo en la prácticade la economicidad y del ahorro, aun siendo válidos para las Administraciones públicas, apenas si son aplicados en realidad. Las razones para ello son tanto de tipo sistemático (ya que faltan los necesarios sistemas de cálculo de costes y de prestaciones, así como otros análisis de economicidad) como personal (ya que la formación de éste es notoriamente insuficiente). $Y$ el caso es que no hay necesidad alguna de empezar desde el principio, ya que existe una teoría económica empresarial pública desde el mercantilismo de los siglos XVII y xVIII. La versión alemana del cameralismo, es decir, de las ciencias cameralísticas, se ocupaba de tres ámbitos: las materias camerales (presupuesto e ingresos del monarca y del Estado, administración y política financiera), las materias policiales (gobierno, Administración general y política económica) y las materias económicas (propiedades fundiarias y forestales, minas, manufacturas, fábricas de moneda, comercio). Tanto 
la doctrina empresarial como la económica tienen su origen en estos tres sectores que siempre se estudiaban desde una perspectiva de economicidad propia y general. Una visión retrospectiva nos permite concluir que la cameralística dedicada a las cuestiones estatales de la Administración y de la economía ha sido la precursora de la teoría empresarial pública, mientras que los estudios sobre temas de economía privada sobre el comercio, el crédito, los bancos y los cambios lo son de una teoría empresarial privada. Es mérito de Ernst KALB el haber retomado esta tradición en su discurso de rector de la Universidad de Köln, el 12 de noviembre de 1927, sobre «Ciencia cameralística y doctrina empresarial comparativa». Ya entonces constató que «el estudio científico de un cuarto ramo, el de la economía empresarial pública, actualmente se encuentra fuera de toda práctica» (19). Pues bien: ¡no tengan que decir lo mismo de nosotros las generaciones venideras! Por ello deberíamos dedicar todo nuestro esfuerzo a ese sector y servir con ello al interés general.

\section{RESUMEN}

El interés general excede del concepto de bienestar, entendido como mera suma de ingresos obtenidos, puesto que se refiere al bienestar completo de todos los sujetos económicos. Desde un punto de vista de la teoría de la empresa, las economías domésticas, las empresas, las asociaciones y las Administraciones públicass contribuyen a él, tanto indirectamente a través de actividades comerciales como directamente a través de cualesquiera actividades que, sin ánimo de lucro, satisfagan las necesidades generales, siendo estas últimas las que dominan en la gestión de las Administraciones y de las empresas públicas. Sus objetivos reales se derivan de encomendaciones públicas que amplian los objetivos formales usuales (balances presupuestarios o rentabilidad) con las categorías de utilidad y costes sociales. La teoría de la empresa debe estudiar con mayor profundidad estas cuestiones: por un lado, hay que revisar en este aspecto las afirmaciones de la teoría general de la empresa, y por otro, hay que desarrollar una teoría específica de la empresa pública.

(19) Ernst KALB, Kmeralwissenschaften und vergleichende Betriebswirtschaftslebre, Köln, 1927 , p. 22. Además distingue el ramo comercial («llamado de forma genérica teoría de la empresa»), la teoría agrícola y el ramo forestal («estática forestal y evaluación de bosques»). 


\section{SUMMARY}

The public welfare exceeds wealth in the sense of realized income and compromises the complete welfare of all persons and institutions. From the point of business administration the private households, enterprises, associations and public administrations contribute to the public welfare either directly by commercial or indirectly by non-profit activities. The last ones dominate in public administration and public enterprises. Their real objectives (budget balance or profitability) by the categories of social benefits and costs. The business administration has to concentrate more on these specific problems: on the one hand the findings of the general business administration are to be reviewed accordingly, the special discipline of the public business administration shall be developed furtheron on the other hand.

Traducción: Julia NiETo KoENIG 
DA-1989, núms. 218-219. PETER EICHHORN. Teoría de la economía de la empresa e interés gene...

DA-1989, núms. 218-219. PETER EICHHORN. Teoría de la economía de la empresa e interés gene... 